\title{
Message of Yoga to humanity
}

\author{
Vijay Kumar Singh* \\ Department of yoga and health, Dev Sanskriti University, India
}

Submission: October 28, 2016; Published: November 03, 2016

*Corresponding author: Vijay Kumar Singh, Department of yoga and health, Dev Sanskriti University, Shantikunj, Haridwar (UK) India.

\section{Opinion}

Yoga is as ancient system of philosophy, life style and techniques that evolves the whole person, the physical, the vital, the mind and emotions, wisdom, ethics and a higher quality of relationships, and the realization of the spiritual reality of each of us. By definition word Yoga means 'unity' or 'oneness' and is derived from the Sanskrit word "Yuj", which means 'to join'. This unity or joining is described in spiritual terms as the union of the individual consciousness with universal consciousness. On a practical level, Yoga is a means of balancing and harmonizing the body, mind and emotions.

According to Yogic tradition, evolution is a systematic process through which we learn to harmonize ourselves. It is a process through which we develop the ability to express our qualities optimally and creatively. As Yoga is a system of personal inquiry and experience. Evolvement is the key concept in the whole of one's life. Yoga is a how we can evolve ourselves this way. Yoga is a complete way of living. For centuries it has made a great contribution to humanity through its methods of physical, mental, intellectual and spiritual development. The science of Yoga has passed the test of thousands of years of trials and refinement.

The great Rishis and Moonies of this land, who renounced the world, studied, mediated and thought upon it in isolation for years together, have developed this science over the millenniums. Therefore, this science is based upon thousands of years of intellectual research by many great sages and saints, who gave actually lived and practiced it. The saints of our ancient Indian culture have been inspiring and giving direction to society by adoption the values of simplicity and high thinking into their lives [1].

\section{Problems of Humanity}

The development of human civilization, mixed with technical advancement and the cultural heritage, has presented a new challenge to mankind; the world is struggling in an effort to establish peace. The sense of pleasure is intimately related to the contemporary social values. In the last few years, technical and economical advancements have created an upheaval in the whole world, resulting in the last few years, technical, progressive shift of attention away from human values. In this wave, stimulated by political and social situations. The importance of economic individualism has surfaced, ignoring the rest of the society. The development and expansion of technology has blocked human interaction, sinking into internal conflict.

As life, having become materialistic has begun to create every type of problem. The chaos in today's world, the problems of the space age, nuclear age, terrorism are escalating so rapidly that people today do not get a chance to relax, have peace and contentment. This world is a very peculiar place, because life as we know it is guided by our ambitions, aspirations, desires and other things which have to be fulfilled. It is the fulfillment of those ambitions and aspirations which make us a worldly person. The moment we are able to recognize that these aspirations and ambitions are just ways and means to keep our consciousness and awareness restricted to the manifest world, to the manifest dimension, and that there is a higher awareness beyond the material world, then that is the beginning of the discovery of the self.

As we become more involved in the manifest world of Manas, Buddhi and Chitta, we subject ourselves to the pains that the manifest world throws at us. These different pains manifest in our body in the form of imbalance, illness, disease. When there is disturbance in the natural ease of the human personality, then that disturbance is known as disease. So disease is nothing, whether it is physical, emotional or psychological or even spiritual, but states of disharmony within the human personality, within human physical and psychological structure, and this state of disease has to be eradicated.

We know that the stress is the root cause of mental and physical problems. Today man has forgotten to relax. Generally 
people resort to televisions, movies or take up excitatory drinks which are suppressants in reality. When there is an imbalance in the sympathetic and parasympathetic nervous system, there is change in endocrine hormonal system. The hormone produced by irregular behavior or tense situations percolates slowly into the cell which is creating and working entity of our body. When there is change in emotions, when person experiences anger, then this feeling reaches the secretory glands, hormones from these glands reach cells changing our physiology, feelings, habits and attitudes. Moreover it percolates deeply into the more subtle level of DNA.

Man today is sick because he thinks he is sick. Sickness and disease have no place in the life of a man who does not accept and tolerate the self limiting thoughts which are the heal seeds of our myriad ailments. We stand hypnotized by the belief that disease and illness are our fats and destiny, rather than health and bliss, which are truly our birth right and heritage [2]. In order to emerge from our mass hypnosis and collective hysteria and to experience health, joy and creative fulfillment, we must make systematic application of yoga in our daily lives

\section{Yogic Relevance for Today}

Modern medicine accepts that the cause of $90 \%$ of diseases is psychosomatic. The cause lies in the mind and symptoms appear in the body. Most diseases are due to mental stress. People with physical diseases, especially those of a chronic nature, and with disturbed mental tranquility, come to yoga for relief.

Yoga emphasized centuries ago, science accepts today, that the psychosomatic problems are results of imbalance in the individual. Yoga practices restore lost balance in the physical, mental and spiritual aspects of human personality, thus providing desired relief from many psychosomatic problems. This is why the suffering people all over the world who deviated from spiritual values are not only accepting yoga as a powerful curative medium, but are moving towards spirituality.

In the present century, a spiritual heritage is being reclaimed of which yoga is very much a part. While central theme of yoga remain the highest goal of the spiritual life, yoga practices gives direct and tangible benefit, to everyone regardless of their spiritual aim. Physical and mental cleansing and strengthening is one of the yoga's most important achievements. It works on holistic principles of harmony and unification. Today yoga is simply a means of maintaining health and well being in an increasingly stressful society. Asana remove the physical discomfort accumulated during a day at the office sitting in a chair, relaxation techniques help to maximize the effectiveness of ever diminishing time off [3].

The only way to eradicate disease and to again obtain total harmony of the personality, to develop an integrated personality, is to adopt a method of self observation and self purification, a method which rebalances and reharmonizes the physiological structure, psychological structure and the spiritual aspirations [4]. Therefore, the practices of yoga such as Ashtanga yoga, Raja yoga, Karma yoga, Bhakti yoga etc. were developed by the seers, who knew that the future generations would have to face these intricate problems.

Gradually, as human life became more and more distorted, disorganized and unbalanced, the great Indian saints had to come out from their caves in the Himalayas and spread this knowledge of yoga across the earth for welfare and upliftment of mankind. Yoga is a process of self discovery. Beyond the needs of individuals, the underlying principles of yoga provide a real tool to combat social malaise. At a time when the world seems to be loss, rejecting past values without being able to establish new ones, yoga provides a means for people to find their own way of connecting with their true selves. Through this connection with their real selves, it is possible for people to manifest harmony in the current age, and for compassion to emerge where hither to there has been none.

Yoga is a discipline which encompasses all the dimensions of the human personality. However due to our distorted mentality, due to our limited perception, limited vision, we consider it to be a physical culture or mental relaxation and concentration. The whole life is yoga, this idea has to evolve, and the whole life is a process of yoga. There is a need to create a yogic revolution in order to bring about a harmony in nations, in philosophies, in thoughts. In this respect, yoga is an aid to establishing new perceptions of what is real, what is necessary and how to become established in a way of life is an experience which cannot be understood intellectually and will only become living knowledge through practice and experience.

Take the problems of the modern era, such psychosomatic ailments like asthma, diabetes, hypertension, heart disease, migraine, spondylosis, and IBS (30\%). Avery large number of those ailments essentially have to be managed in multidimensional way, and they cannot be tackled in a linear modality as we have been doing, either with infectious and contagious diseases or with the usual surgical operations [5]. Unless we have this multidimensional approach of the physical, mental, emotional and intellectual levels and at the base, the spiritual level, we will not be able to solve these multidimensional problems of the modern era. For that we have a series of techniques available to us.

At physical level we have yoga asana, cleaning techniques, and many other things to deal with the physical body to bring about the necessary transformation. At mental level we have two aspects. One is the mind, the other is the emotions. To deal with the science of emotion, we have Bhakti yoga (devotion towards almighty), the devotional sessions etc [6]. all these things deal with Manomaya kosha (physical sheath). In fact, the Manomaya Kosha is the base where these imbalances start. To deal with mind and emotions we have the entire system of Raja Yoga 
(Patanjali yoga) - Dharana, Dhyana, Samadhi $[7,8]$.

Now is the time we need to transform restrictive lifestyle and adopt the principles of yoga in our lifestyle, then life begins to blossom like flower and for this we need to adopt path of biological engineering which is a path of yoga. It develops a different energy, different awareness which gives birth to a spiritual principle in the life. There is an urgent need to establish balance between material and spiritual life. Materialism and spiritualism are the two wings on which we need to fly high and human life is made worthwhile. This is the message of yoga to humanity.

\section{References}

1. Anantharaman TR (2007) The Ancient Yoga and Modern Science. The History of Indian Science, Philosophies \& Culture.
2. Bhole MV (1983) Yoga and Promotion of Health Care. Yoga Mimamsa 22(132): 80-83.

3. Swami Satyanand Saraswati (1969) Asana Pranayama Mudra Bandha. Yoga Publication Trust.

4. Nagendra HR, Nagarathana R (1983) Application of integrated approach of yoga: A review. Yoga Review 3(4): 173-94.

5. Saraswati, Swami Karmananda (1983) Yogic Management of Common Diseases. Yoga Publication Trust.

6. Saraswati, Swami Satyanand (2002). Bhakti Yoga Sagar. Yoga Publication Trust.

7. Suman kk, Ahluwalia V K (2010) Yoga Therapy. Lotus press.

8. Rishi Vivekananda (2005) Practical Yoga Psychology. Yoga Publication Trust.

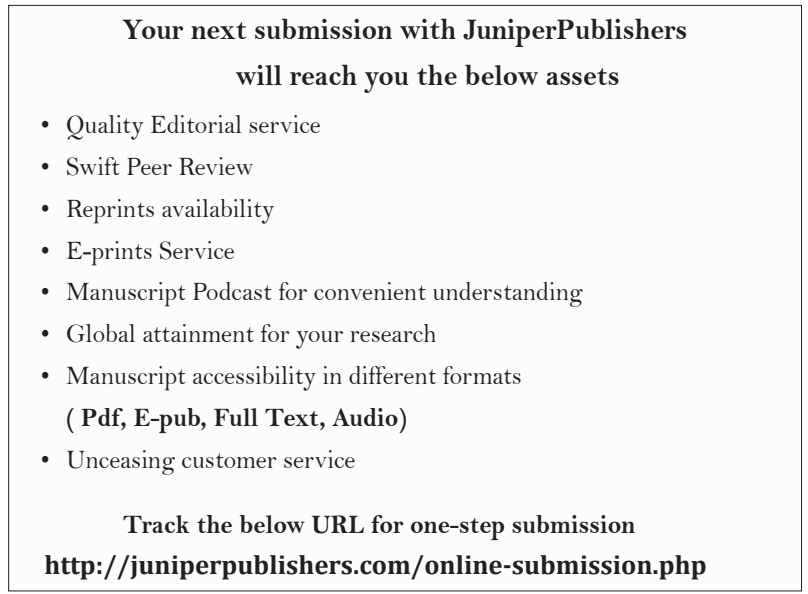

